\title{
Bachelor of Education Teacher Trainees' Information Evaluating Ability and Utilization of E-resources at the University of Nairobi, Kenya
}

\author{
John Njoroge Kanori, Paul Amollo Odundo*, Hellen Nasimiyuh Inyega* \\ Department of Educational Communication and Technology, University of Nairobi, Nairobi, Kenya \\ Email address: \\ kanori2015@gmail.com (J. N. Kanori), odundopaul@yahoo.com (P.A. Odundo), hinyega@yahoo.com (H. N. Inyega) \\ ${ }^{*}$ Corresponding author
}

\section{To cite this article:}

John Njoroge Kanori, Paul Amollo Odundo, Hellen Nasimiyuh Inyega. Bachelor of Education Teacher Trainees' Information Evaluating Ability and Utilization of E-resources at the University of Nairobi, Kenya. Teacher Education and Curriculum Studies.

Vol. 5, No. 3, 2020, pp. 125-134. doi: 10.11648/j.tecs.20200503.22

Received: July 12, 2020; Accepted: August 5, 2020; Published: August 31, 2020

\begin{abstract}
Utilization of e-resources by Bachelor of Education Teacher Trainee exposes the learner to up-to-the minute information in multimedia format such as Compact Disk Read Only Memory (CD-ROM) databases, e-journals, institutional digital resources and video recordings among other resources. To benefit from accessing quality information from e-resources, trainees are supposed to evaluate resources. However, there have been complaints from library staff and faculty that trainees of the University of Nairobi were inadequately inducted on evaluation of e-resources. The trainees hardly utilize e-resources while experiencing difficulties in evaluating sources for quality. The study examined trainees' evaluating ability. The objective of the study was to establish trainees' evaluating ability and utilization of e-resources. The study adopted descriptive survey design. Stratified random sampling was used to identify 370 teacher trainees and data was collected using questionnaires, interview guides and document analysis guide. Validity was ascertained using the faculty involved in teacher training processes. The instrument demonstrated high internal consistency $(>.90)$ using test-retest method. Data was analyzed using descriptive and inferential statistical techniques to establish the relationship between trainees evaluating ability and utilization of e-resources. The findings revealed a significant statistical association between trainees' evaluating ability and utilization of e-resources. The study recommended that a policy be formulated at the University of Nairobi requesting trainees to attend information literacy sessions conducted by the library. The trainees should be taught evaluation criteria to improve learners' practices of assessing accuracy, currency, objectivity, coverage and authority of information that support academic tasks. Replication of a longitudinal study should be undertaken to monitor trainees' evaluating ability from first year to fourth year.
\end{abstract}

Keywords: Bachelor of Education, Teacher Trainees, Information, Evaluating Ability, Utilization, E-Resources

\section{Introduction}

Utilization of e-resources is a reading culture that enables information seekers to access vast amount of information to advance creation of knowledge. Teacher trainees of University of Nairobi benefit from utilizing e-books and other digital resources by exposing the learners to up-to-date information that support completion of academic assignments [1]. But proliferation of e-resources requires trainees to filter unreliable documents by applying the evaluation criteria so as to utilize reliable and authentic sources. Librarians are responsible for guiding trainees on evaluation criteria which filters unreliable internet sources [2]. Readers conversant with evaluation criteria assess e-resources for quality of information. The evaluation criteria revolve around assessing e-resources for currency, coverage, accuracy, objectivity and authority to ensure that the information accessed support completion of trainees' academic tasks. Information seekers competent in applying currency criteria confirm that eresources' date of publication is up to date and support current research. Information seekers with adequate skills in applying coverage criteria confirm that all topics which the eresource purports to cover are actually included in the content. The users go through the table of content, preface 
and the index to confirm that all the topics were covered adequately and if the topics were not covered exhaustively, the document is abandoned [3]. Competency in using the objectivity criteria imply that users go through the e-resources to check whether the articles present different views of a topic and include the advantages and disadvantages of each side [4]. The information seeker also checks whether neutral language is used throughout the article to ensure no abusive language is used by the author. Information seekers also confirm that the author use a language that does not discriminate anybody on the bases of race or gender. Information seekers conversant with accuracy criteria confirm that sources of factual information are presented in the reference list to facilitate tracing of the documents to countercheck accuracy of figures. Information seekers also ensure that the resources are free from grammatical and typographical errors to enhance reliability of data [3]. Furthermore, information seekers possessing adequate skills of applying the authority criteria to assess e-resources for quality, check the qualifications of authors to confirm the expertise of the authors. Resources prepared by credible authors and well known publishers are reliable and suitable to integrate to academic work [5]. Information evaluating ability boosts utilization of e-resources to develop quality articles that earn the trainees high grades in exams. Information seekers evaluate internet sources for quality to eliminate sources prepared by authors who are not subject experts [6]. Trainees have inadequate evaluating abilities which impede utilization of e-resources by the learners to write scholarly papers or complete academic tasks.

\section{Literature Review}

\subsection{Benefits of Utilizing E-resources}

The University of Nairobi subscribes to various eresources which are utilized by the academic community to advance teaching, learning and research activities. Eresources store information electronically and access is through electronic systems like computers, lap-tops and mobile phones [7]. E-resources include: e-books, e-journals, e-databases, e-reference sources, digital institutional repositories, e-archives, e-newspaper, and e-conference papers [8]. E-resources promote teaching, learning and research [9]. Teachers use e-books to teach complex concepts or to increase student motivation to learn because the resources are interactive [10]. Furthermore, e-books allow classes or groups to read, comment upon and discuss an ebook communally, in real time. Additionally, the benefits offered by e-resources include access to the resources by anyone, from anywhere, at any time and ease of searching the text which could be in any media [12]. The University of Nairobi has adopted the e-resources reading culture after realizing the benefits that accrue to readers who utilize the resources. Science or Arts teacher trainees can access various types of e-resources like e-journals or e-conference papers. The university avails core textbooks online through the ekitabu platform at (https://uon.ekitabu.com) which is linked to the library services portal https//www.uonbi.ac.ke [13]. Trainees access core textbooks online to complete assignments. It is the responsibility of each trainee to evaluate e-resources before utilizing the information to advance course related activities

\subsection{Evaluation Criteria and Utilization of Resources}

Information literacy enhances searching, evaluation and utilization of e-resources by information seekers to write scholarly papers or complete assignments. Efficient utilization of e-resources is achieved through improving the information literate abilities of trainees of University of Nairobi [14]. Conversance with the evaluation criteria enhances utilization of resources by the trainees. Evaluation involve scrutinizing e-books, e-journals, video recordings and other web-based resources to assess the quality of sources before utilizing the information to complete academic work. Evaluation of sources of information should be done when undertaking research [5]. This implies that the information seeker has the responsibility of evaluating sources before utilizing the information. This precautionary measure is necessary because many resources circulating are unreliable and information literate teacher trainees avoid such unauthenticated sources by evaluating the documents. Evaluating resources involve determining information needed and purpose [15]. For instance, reliable sources such as subject encyclopedia, peer-reviewed e-journal articles, websites that undergo regular process of review and e-books like e-kitabu textbooks written by experts in the field best serve the purpose of assisting trainees to write scholarly papers. The evaluation criteria that empower information seekers with the ability to assess resources for quality include authority, objectivity, currency, accuracy and coverage [15]. This study examined trainees' competence in evaluating information resources for quality by applying authority, objectivity, currency, accuracy and coverage criteria.

\subsubsection{Evaluation Criteria: Authority}

Sources of information are evaluated by applying the authority criteria to confirm the expertise of the author before utilizing the information. However, some authors avail low quality resources in the market by failing to submit the articles to peer-reviewers. Information appearing in the internet is not always peer-reviewed because some authors of online articles are not experts in the field and the information may not be authentic [6]. Some online documents are not scrutinized by an editorial board comprising experts in the field. Competent information seekers assess the quality of sources using the authority criteria by confirming authors' credentials and experience in writing relevant and reliable articles. Information seekers confirm that the authors are faculty members and experts in the field. Faculty members publish quality articles in reputable peer-reviewed journals that cover current developments in the field. Trainees benefit from reading authentic information which add value to articles written by the learners [6]. Users have the responsibility of confirming authors of resources and 
authenticity of information [16]. This implied that information seekers confirm credentials of the authors to determine that the writer is an expert in the subject. Some authors of e-resources write on topics they are not conversant and push such articles to e-journals that are not peerreviewed. The shortcomings of such an arrangement is that information seekers like trainees are exposed to unauthenticated literature which do not assist learners to submit quality academic work. Competent information seekers consult resources written by authors who are authority in the subject [5]. Two categories of authors writing reliable and authentic works include those who share research results with other scholars and those who write articles for the general public. Information seekers confirm that resources consulted are published by reputable publishers but not from predatory journals. Predatory journals exploit authors by charging fees to publish articles which are not peer-reviewed by an authorized and experienced editorial board. Authors submitting articles to predatory journals and information seekers are cheated because the papers are not recognized in the publishing industry. Information seekers are responsible of confirming whether the publisher and sponsoring body are experienced in publishing reliable resources [3].

\subsubsection{Evaluation Criteria: Objectivity}

E-resources are assessed for objectivity to ensure that different views of a topic are included in an article. Objectivity criteria confirm whether the author use unbiased language throughout the document. Information seekers confirm that different views of a topic and the advantages and disadvantages of each are reported in the document to broaden the knowledge of users [4]. Information seekers ascertain that writers use unbiased language to allow readers to acquire balanced knowledge which is not influenced by the authors. If the writer uses discriminating language that portray one religion as superior than others, the information seeker is advised to abandon the article and choose sources that use unbiased language. Experienced information seekers confirm that the source being consulted is unbiased and objective before utilizing the information to advance research or complete academic tasks [15].

\subsubsection{Evaluation Criteria: Currency}

E-resources are assessed for up-to-datedness of information to ensure teacher trainees utilize sources that report current developments in research that assist the learners to write quality scholarly papers. Furthermore, learners, lecturers and researchers apply the currency criteria to confirm the date of publication as the timeliness of the information affect usefulness of e-resources [16]. The University observed that the date of publication assists information seekers to decide whether the information is current or outdated. The date of publication guides information seekers in need of current or retrospective information. For instance, users in need of current information choose sources published recently (2020) to access up-to-date and relevant articles. Further, websites ought to have evidence on the "last updated" statement to help users assess whether the information is current. Users researching on a topic go through latest literature to find gaps in knowledge. Additionally, users assess the date of publication as information changes over time and new developments occur in a field of knowledge [5]. However, although old publications do not cover new developments in a subject, users in need of retrospective information find the sources useful by providing a rich background of the topic of research. While emphasizing the importance of retrospective information, [15] confirmed that users want older sources if the topic of research requires a historical background like "History of information literacy instruction in high schools in Kenya".

\subsubsection{Evaluation Criteria: Accuracy}

Accurate information is required in all fields of knowledge to support research carried out by scholars. Sources are evaluated by applying accuracy criteria to confirm that the list of references given in the publication/document facilitate verification of the information [6]. Researchers, lecturers and learners competent with accuracy criteria confirm authenticity of factual information presented in e-resources by checking the same figures from sources appearing in the publications' reference lists. Referencing facilitate tracing of articles describing full research in detail to confirm the accuracy of factual information and statistical data presented by an author [17]. Additionally, Information seekers ensure that the resources are free from grammatical and typographical errors appearing in the content due to ambiguous presentation of findings. Information seekers confirm that the source of data is clear to establish accuracy of information to allow users make correct and firm decisions [5]. Furthermore, users require accurate facts and figures to develop articles that are accepted by peer-reviewed journals because of presenting correct information. While contributing to accuracy criteria debate, [3] affirmed the importance of confirming the error rate, presence of mis-spelt words and correct bibliographic citations in the resource before utilizing the information to ensure presentation of high quality scholarly work.

\subsubsection{Evaluation Criteria: Coverage}

Information seekers confirm that the resources being consulted cover topics exhaustively to decide which sources to utilize to write high quality articles in a specific field of knowledge. Information seekers proficient in applying coverage criteria ascertain that the e-resources being evaluated cover topics purported to be covered [16]. The users compare coverage of topics in one e-database with coverage of the same topics in other sources to confirm that topics were treated exhaustively. Similarly, [3] asserted that information seekers compare the stated subject coverage with the actual subjects covered by the resources. Additionally, information seekers confirm that the titles covered are appropriate to the subject by verifying the topics covered in the document. Verification is important because some titles mislead users by presenting a different subject other than that reflected in the title. Furthermore, information seekers 
conversant with the coverage criteria confirm that the content is international as purported by the author by perusing the topics appearing in the e-journal or Compact Disk Read Only Memory (CD-ROM) database.

\section{Undergraduates' Evaluating Ability and Utilization of E-resources}

Undergraduates have been assessed to establish whether learners evaluate resources to confirm that the information is of high quality. For instance, the undergraduates of the University of Hawaii desired to be taught the evaluation criteria because of not being familiar with the topic [18]. The undergraduates of the university experienced difficulties of evaluating e-resources for quality because of possessing inadequate evaluating skills. Quality information refer to articles that are relevant, accurate, current and authoritative. Similarly, the study has affirmed that use of e-resources is inhibited by learners' inadequate skills and knowledge in search, retrieval and evaluation of information [19]. This implied that learners with inadequate evaluating skills utilize information retrieved from online resources without scrutinizing the sources for quality. This situation of utilizing inaccurate and unreliable information is of concern because learners develop low quality articles that do not meet the threshold of being published by peer-reviewed journals. Furthermore, undergraduates gleaning information from resources that have not been evaluated fail to present high quality academic work. Likewise, it has been observed that learners do not evaluate web-based resources and some fail to use e-resources at all because of possessing inadequate evaluating skills [20]. Similarly, learners do not always use the evaluation criteria because of not being conversant with the criteria [21]. Undergraduates do not apply the evaluation criteria of currency, coverage, authority, objectivity and accuracy to judge the quality of information to use to advance academic work [22]. This implied that the learners utilized resources irrespective of the quality. Furthermore, learners consulting Wikipedia for background information of a research topic utilize inaccurate information as the source is not authentic [23]. Learners consulting Wikipedia are not conversant with the evaluation criteria because the source is not authoritative [15]. The present study emphasizes that Wikipedia is not reputable for publishing scholarly works because the articles are not peer-reviewed. The above studies confirm that learners from various academic institutions experienced difficulties of evaluating e-resources for quality information to complete assignments. This situation impedes utilization of e-resources by undergraduates. However, universities in developed countries are committed to empowering the undergraduates with information literate abilities because the skills assist the learners to develop analytical and evaluating skills that help students to excel in academic work. The learners are empowered with evaluating skills that are vital in choosing relevant, accurate, reliable and credible sources to consult when writing scholarly articles.
Learners to use online databases subscribed to by the library to get quality information for research topics [24]. Similarly, the study has confirmed that only $42 \%$ (3.52) teacher trainees rated themselves good before undertaking an evaluation course and the number increased to $64 \%$ (3.93 in the rating scale 1-5) after attending the course indicating that the learners improved information source evaluating ability [25]. Additionally, librarians at the University of California Berkeley collaborate with faculty in preparing and teaching information literacy embedded in "Introduction to Environmental Science course" by providing links to relevant online resources and guiding undergraduates on evaluation of information [26]. The present study is of the view that empowering teacher trainees with evaluating ability would expose the learners to vast subject contents that boost utilization of e-resources.

\section{Statement of the Problem}

The University of Nairobi Library subscribe to a variety of e-resources comprising of over 1,198,348 e-books, over 186,562 e-journals and over 1,221,045 digital resources of the University of Nairobi's institutional repository (https://www.uonbi.ac.ke) [13]. Trainees are expected to utilize e-resources from anywhere anytime using electronic devices like personal computers, laptops or mobile phones via remote access. Trainees benefit from utilizing e-resources through exposure to-up-to-the-minute information in multimedia format such as Digital Versatile Disks (DVDs), CD-ROM databases, e-books, e-thesis, e-archives and ejournals. The advantages of utilizing e-resources include ease of use, speed of search, providing links to vast digital resources outside the library, access to e-resources any time anywhere and access to multiple files. In an ideal situation trainees conversant with evaluation criteria assess the quality of resources before utilizing the information to confirm authenticity of the source. Trainees competent in applying accuracy criteria confirm that factual information presented by a source is correct by verifying statistics from the references listed in the document. Moreover, trainees conversant with currency criteria check the date of publication to ascertain that the information is up-to-date and suitable for preparing articles on current research. Additionally, trainees competent in using authority criteria confirm that the author is qualified in the field by checking the credentials of the writer/producer. Furthermore, trainees conversant with objectivity criteria confirm that the writer uses unbiased language throughout the source. Teacher trainees knowledgeable in applying coverage criteria confirm that all topics purported to be covered are included in the source being evaluated. Trainees conversant with the evaluation criteria develop quality articles because of using authentic sources. However, library staff and faculty complained that trainees were not guided adequately on evaluation of e-resources. As a result of this trainees utilize resources that have not been evaluated for accuracy, objectivity, authority, coverage and currency. This might lead to trainees developing low quality academic work. This 
worrisome situation of trainees possessing inadequate evaluating abilities was detected during the Fifth and Sixth University of Nairobi Library Open Week held in October 2015 and 2016 at the Kenya Science Campus (KSC) and at the College of Education and External Studies (CEES) Kikuyu respectively. Trainees from second year to fourth year were requested to demonstrate skills of evaluating eresources subscribed to by the library. Trainees selected eresources to utilize without evaluating the sources. Additionally, the trainees confessed to have never been taught the evaluating criteria. There was need to carry out a study on trainees' information evaluating abilities and utilization of e-resources to shed more light on the topic.

\section{Theoretical Context}

The study was guided by the System Theory based on Ludwig von Bertalanffy's ideas which revolved around the science field. In 1951 Von Bertalanffy argued that the science field studied forms of systems like the human body that was composed of interrelated subsystems and emphasized that survival of the system was dependent on the contributions of subsystems to the overall purpose of the system [27]. Systems theory was improved in the 1950 s by Trist, Bamforth, Rice, Khan, Katz and Boulding [28]. Katz and Khan contributed by enlarging the subject of subsystems in managerial theory through distinguishing five types of subsystems identified at work place in social organizations. The sub-systems include production, supportive, maintenance, adaptive and managerial sub-systems which work in unison to increase the organization's (system's) productivity [29]. Boulding improved systems theory by constructing a hierarchy of systems from level 1 to level 8 based on the degree of complexity. The hierarchy started with Level 1 which was a static framework like painting, level 2 dynamic system like the solar system, level 3 control systems like the computer, level 4 life forms, level 5 plant forms, level 6 animal forms, level 7 human being and level 8 social organization which is the most complex system. Trist and Bamforth's contribution was the introduction of the concept of socio-technical systems prevalent in organizations. Effective work in organizations was viewed as a function of interdependence of technology (equipment) and social needs (relationship within groups). Rice improved the theory further by suggesting that there are two main systems in a firm; an operating and a managing system where the former deals with import, conversion and export of products and services while the latter deals with the control, decisionmaking and communication aspects of the whole system. The two systems are interdependent and work in unison to achieve organizational goals. Systems theory holds that there are two types of systems; closed or open system. A closed system does not interact with the environment while an open system is made of many inter-dependent parts and accept inputs from the environment. The inputs are transformed through process into outputs which is returned to the environment ready to be absorbed by other systems as input and the cycle continues. Teacher training programme is an open social system that communicates with the environment by accepting inputs and releasing outputs. A vital input in trainees' programme is information literacy. The trainees are guided on how to assess e-resources through application of the evaluation criteria of currency, accuracy, objectivity, coverage and authority before utilizing the information. Subsystems like library, curriculum and communication skills departments play a vital role in trainees' learning process so that the learners acquire the skills (input). The process aspect involves trainees internalizing the evaluation criteria through frequent hands-on exercises of scrutinizing eresources. The trainees are transformed into competent learners who evaluate e-resources for quality before utilizing information. Trainees competent in evaluating e-resources utilize quality information ethically to solve academic and societal problems. The quality papers written by trainees are the output released to the environment. The theory informs the study through viewing the training programme as a subsystem within the University of Nairobi education system. The teacher training programme is made up of interrelated subsystems like the library, transport, curriculum and games departments which contribute towards producing competent trainees. Systems theory informs the study through viewing the evaluation criteria of currency, accuracy, coverage, authority and objectivity as vital inputs into the trainees' learning process where the learners become responsible of assessing sources for quality before utilizing information. The theory informs the study that to gain competency in evaluation criteria, the trainees are supposed to undergo a transformation process by having several hands-on-practical exercises of evaluating the resources Additionally, the theory informs the study that competent trainees use peer-reviewed resources to write scholarly articles (output) that are absorbed by the environment to solve societal problems. The quality articles (output) help the trainees to graduate successfully. The University of Nairobi achieves the goal of educating trainees that contribute in developing the Kenyan economy.

\section{Methodology}

The study used descriptive survey design to collect and analyse data. The target population for the study was composed of teacher trainees and staff from KSC and CEES Kikuyu Campus. The target population comprised of 3082 teacher trainees from second to fourth year enrolled in the 2016/2017 academic year, 10 librarians from KSC and CEES libraries, 66 lecturers, four administrators and two information skills librarians. The study used both probability and non-probability sampling procedures. Stratified random sampling procedure was used to sample $12 \%$ of 3082 trainees to yield a sample size of 370 trainees. Purposive sampling was used to select 6 librarians from KSC and CEES libraries, 20 lecturers, two administrators and two information skills librarians who teach trainees information skills course. Data was collected using questionnaires, interview guides and document analysis guide. Content validity was ascertained 
using the faculty concerned with trainees' education processes and reliability test yielded 0.90 Cronbach's coefficient alpha. Data was analyzed using descriptive and inferential statistics.

\section{Findings of the Study}

Trainees' information evaluating ability and utilization of e-resources

The study examined trainees' information evaluating ability and utilization of e-resources. The trainees were supposed to evaluate e-resources so that credible sources were utilized to complete assignments while propaganda and unreliable documents were abandoned. The trainees were asked to rate conversance with coverage, objectivity, accuracy, currency and authority criteria. Figure 1 shows trainees' conversance with the evaluation criteria which was rated using a four-point scale of excellent, good, average and poor.

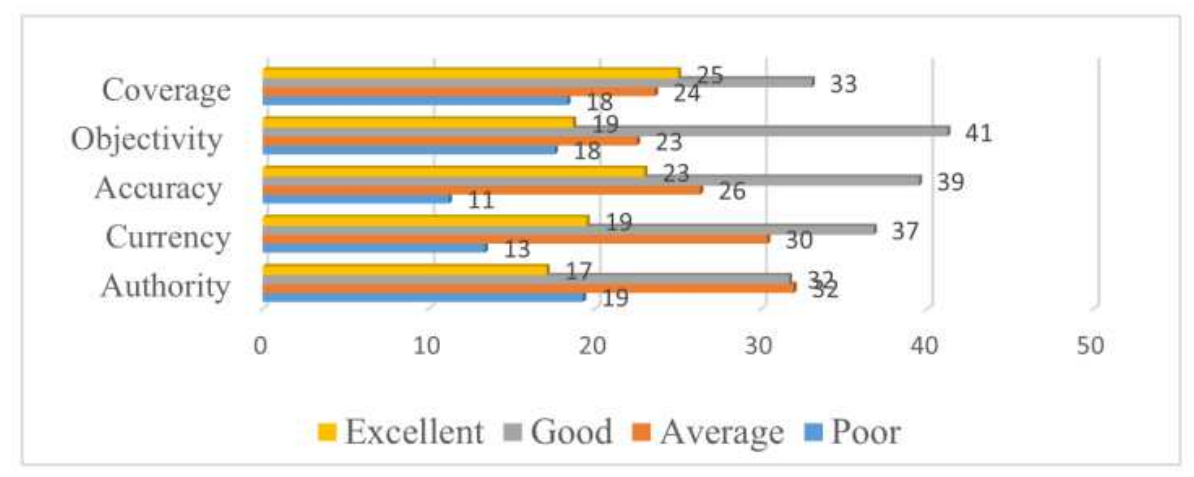

Figure 1. Trainees' conversance with evaluation criteria.

The findings indicated that $92(25 \%)$ trainees' conversance with coverage criteria was excellent, whereas $122(33 \%)$ trainees rated conversance with coverage criteria as good. This implied that 214 (58\%) trainees were conversant with confirming whether the resources evaluated covered all the relevant topics in a specific subject. The interpretation was that more than half $(58 \%)$ of the trainees apply the coverage criteria to confirm whether the resources being consulted have included relevant topics in a subject. More findings affirmed that $88(24 \%)$ trainees rated conversance with coverage criteria as average while $66(18 \%)$ trainees rated conversance with coverage criteria as poor. This implied that $154(42 \%)$ trainees were incapable of confirming whether the e-resources being evaluated covered all the topics purported to be covered. The study is of the view that 154 trainees use information without confirming that subject coverage of the resource is exhaustive. The interpretation is that a high percentage $(42 \%)$ of trainees utilize e-resources without confirming whether the documents cover all topics of interest. This is worrisome because the trainees may fail to complete assignments on time because of wasting time with documents that are abandoned later for not covering the topic of research exhaustively. Further findings revealed that 70 $(19 \%)$ trainees rated conversance with objectivity criteria as excellent while $151(41 \%)$ rated conversance with objectivity as good in evaluating e-resources. The implication was that $221(60 \%)$ trainees were familiar with checking the objectivity of e-resources by confirming that the author used neutral language and included different views on controversial issues in the article. More findings indicated that $85(23 \%)$ trainees rated conversance with objectivity criteria as average whereas $66(18 \%)$ trainees rated conversance with objectivity as poor in evaluating e- resources. The interpretation was that 151 (41\%) trainees submit low quality assignments that do not include different views of a topic because of not applying objectivity criteria when evaluating e-resources. Furthermore, the findings confirmed that $85(23 \%)$ trainees rated conversance with accuracy criteria as excellent in evaluating e-resources while $144(39 \%)$ rated conversance with accuracy criteria, as good in evaluating e-resources before utilizing the resources. This implied that $229(62 \%)$ trainees were able to verify from other sources whether the e-resources being evaluated present factual information accurately. However, 96 (26\%) trainees rated conversance with accuracy as average in evaluating e-resources whereas $40(11 \%)$ trainees rated conversance with accuracy as poor in evaluating e-resources. This suggested that $136(37 \%)$ of the trainees did not consult other sources to confirm whether the e-resources being evaluated present factual information accurately. This situation is of concern because $37 \%$ of trainees may be submitting assignments with inaccurate information. Moreover, findings indicated that $70(19 \%)$ trainees rated conversance with currency criteria as excellent in evaluating e-resources whereas 136 (37\%) trainees rated conversance with currency criteria as good in evaluating e-resources. Findings affirmed that $206(56 \%)$ trainees are conversant with verifying the date when the e-resources being evaluated were created to determine whether the information presented is current or outdated. The findings corroborated with the study which established that $91.1 \%$ undergraduates had the ability to evaluate information from web-based resources by applying authority, appropriateness and currency criteria [30]. Similarly, the findings agreed with the study which revealed that majority of undergraduates in Greece rated 'sources with up-to-date facts' as "very important' (mean 
2.42) on a scale ranging from $0=$ 'I don't know', $1=$ 'not so important', to $3=$ 'very important' [31]. However, 111 (30\%) trainees rated conversance with currency criteria as average in evaluating e-resources while 48 (13\%) trainees rated conversance with currency criteria as poor in evaluating eresources. This suggested that $159(43 \%)$ trainees failed to assess the currency of information gleaned from e-resources and this lowers the quality of academic work submitted to the faculty. Additionally, the findings revealed that $62(17 \%)$ trainees rated conversance with authority criteria as excellent in evaluating e-resources while 118 (32\%) trainees rated conversance with authority criteria as good. This implied that $180(49 \%)$ trainees were conversant with scrutinizing the credibility of the e-resources before utilizing the resources. More findings confirmed that 118 (32\%) trainees rated conversance with authority criteria as average whereas 70 (19\%) trainees rated conversance with authority criteria as poor in evaluating e-resources. The implication was that 188 (51\%) trainees did not apply the authority criteria to confirm expertise of the author before utilizing information gleaned from e-resources. This meant that assignments submitted to the faculty by trainees are of low quality because of consulting sources that are written by authors who are not experts in the subject. The findings corroborated with the study which revealed that majority 18 (58\%) of undergraduates of the University of Nairobi have inadequate skills of identifying credible sources to utilize for academic purposes from the internet [32]. The study confirmed that trainees utilize unreliable information unknowingly due to inability to evaluate sources for quality. The study examined the issues that arose as trainees utilized e-resources. Trainees were asked to rate ease of evaluating e-resources to complete academic tasks.

Figure 2 presents responses indicating whether the trainees experienced difficulties when applying coverage, objectivity, accuracy, currency and authority criteria to evaluate reliable sources.

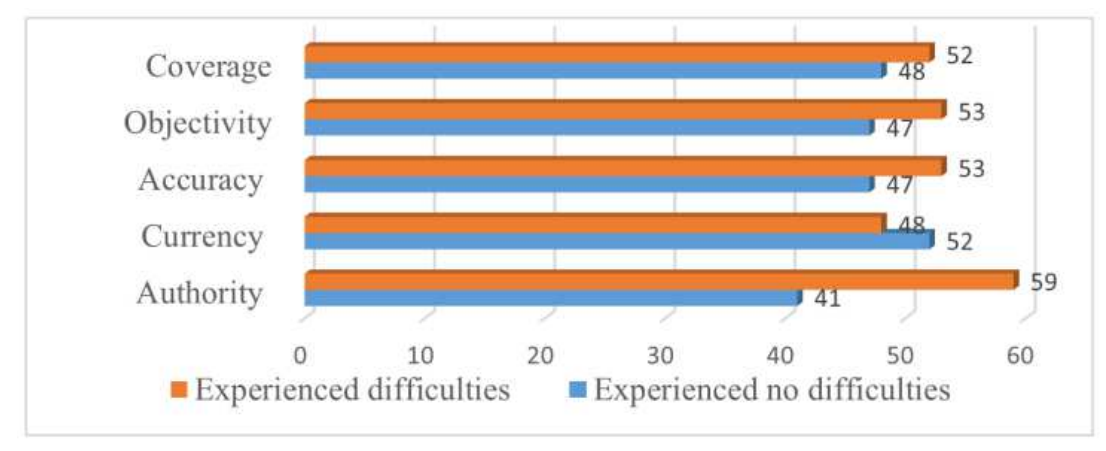

Figure 2. Issues arising from adoption of evaluation criteria by trainees.

Findings revealed that $182(52 \%)$ trainees experienced difficulties when applying coverage criteria to assess the quality of information obtained from e-resources. This suggested that $52 \%$ of trainees could not easily determine whether the e-resources being utilized covered the topic of interest exhaustively to support completion of assignment successfully. The findings affirmed that $186(53 \%)$ trainees were not comfortable with applying objectivity criteria. The criteria assess whether the author uses unbiased language or includes divergent views throughout the source to allow the reader to decide which side to support. Furthermore, the findings revealed that $186(53 \%)$ trainees found it difficult to apply accuracy criteria to assess whether the information presented is correct. Accuracy criteria involve comparing information presented in the e-resources being evaluated with that presented by other sources to confirm accuracy of facts and figures. The findings in Figure 2 affirmed that out of 370 trainees, 207 (59\%) learners had difficulties of applying the authority criteria to determine the credibility of sources of information. This suggested that the trainees had difficulties of confirming that the authors of the e-resources are experts in the field. The exercise entails checking academic and professional qualifications of authors of the articles appearing in the e-resources being evaluated. Further, findings indicated that $166(48 \%)$ trainees had difficulties of applying currency criteria to evaluate e-resources to establish up-to-datedness of the information presented by the source. The study has established that more than half $(50 \%)$ of trainees experienced difficulties of applying coverage, objective, accuracy and authority criteria to confirm the quality of e-resources before utilizing information for academic purposes. However, less than half (48\%) of trainees experienced difficulties of applying currency criteria to evaluate e-resources implying that majority (52\%) are familiar with the criteria. This implied that difficulties of applying evaluation criteria experienced by trainees impede utilization of e-resources. Additionally, the trainees may end up developing low quality seminar papers or student projects because of utilizing low quality e-resources. To assess whether there were variations on the trainees' evaluating ability among different courses, a cross tabulation between the courses pursued by the learners and the evaluation criteria was carried out. Trainees' evaluating ability across different courses, that is Bachelor of Education (B.Ed) Arts, B.Ed (Science), B.Ed Physical Education (PE) and Sports option, B.Ed (Early Childhood Education) and B.Ed Information Communication and Technology (ICT) was rated using a scale ranging from 'Not conversant at all', 'not so conversant', 'conversant', and 'very conversant'. The results were presented in Table 1. 
Table 1. Trainees'evaluating ability across different courses.

\begin{tabular}{|c|c|c|c|c|c|c|}
\hline & & \multicolumn{4}{|c|}{ Rate of conversance with authority criteria } & \multirow{2}{*}{ Total } \\
\hline & & not conversant at all & not so conversant & Conversant & very conversant & \\
\hline \multirow{3}{*}{ B.Ed (Arts) } & Count & 44 & 72 & 62 & 37 & 215 \\
\hline & $\%$ within course & $20.5 \%$ & $33.5 \%$ & $28.8 \%$ & $17.2 \%$ & $100 \%$ \\
\hline & $\%$ within rate in conversance in authority & $62.9 \%$ & $62.1 \%$ & $54.9 \%$ & $59.7 \%$ & $59.6 \%$ \\
\hline \multirow{3}{*}{ B.Ed (Science) } & Count & 15 & 12 & 23 & 11 & 61 \\
\hline & $\%$ within course & $24.6 \%$ & $19.7 \%$ & $37.7 \%$ & $18.0 \%$ & $100 \%$ \\
\hline & $\%$ within rate in conversance in authority & $21.4 \%$ & $10.3 \%$ & $20.4 \%$ & $17.7 \%$ & $16.9 \%$ \\
\hline \multirow{3}{*}{$\begin{array}{l}\text { B.Ed (P.E and } \\
\text { Sports) }\end{array}$} & Count & 5 & 11 & 11 & 4 & 31 \\
\hline & $\%$ within course & $16.1 \%$ & $35.5 \%$ & $35.5 \%$ & $12.9 \%$ & $100 \%$ \\
\hline & $\%$ within rate in conversance in authority & $7.1 \%$ & $9.5 \%$ & $9.7 \%$ & $6.5 \%$ & $8.6 \%$ \\
\hline B.Ed (Early & Count & 2 & 10 & 1 & 1 & 14 \\
\hline Childhood & $\%$ within course & $14.3 \%$ & $71.4 \%$ & $7.1 \%$ & $7.1 \%$ & $100 \%$ \\
\hline Education & $\%$ within rate in conversance in authority & $2.9 \%$ & $8.6 \%$ & $.9 \%$ & $1.6 \%$ & $3.9 \%$ \\
\hline \multirow{3}{*}{ B.Ed (ICT) } & Count & 4 & 11 & 16 & 9 & 40 \\
\hline & $\%$ within course & $10.0 \%$ & $27.5 \%$ & $40.0 \%$ & $22.5 \%$ & $100 \%$ \\
\hline & $\%$ within rate in conversance in authority & $5.7 \%$ & $9.5 \%$ & $14.2 \%$ & $14.5 \%$ & $11.1 \%$ \\
\hline \multirow{3}{*}{ Total } & Count & 70 & 116 & 113 & 62 & 361 \\
\hline & $\%$ within course & $19.4 \%$ & $32.1 \%$ & $31.3 \%$ & $17.2 \%$ & $100 \%$ \\
\hline & $\%$ within rate in conversance in authority & $100 \%$ & $100 \%$ & $100 \%$ & $100 \%$ & $100 \%$ \\
\hline
\end{tabular}

The findings in Table 1 revealed that $116(54 \%)$ trainees pursuing B.Ed (Arts) were not conversant with authority criteria. The following verbatim findings confirm that majority of B.Ed (Arts) trainees were not conversant with the evaluation criteria. Trainees were asked to highlight conversance with the evaluation criteria. A second year female teacher trainee taking English/Linguistics combination had this to say: "I'm not familiar with the evaluation criteria for assessing sources for quality. The topic was not covered during the information skills class and I was unlucky to have missed a library workshop in second year where the facilitator tackled the topic. I find it cumbersome to evaluate the numerous online resources availed by the library because publication details like the author, editorial board and peer-review process is not clear" This suggested that majority of trainees taking B.Ed (Arts) utilized e-resources that have not been evaluated for relevancy and credibility. This situation is of concern because the academic work developed by trainees may be of poor quality. However, 99 (46\%) B.Ed (Arts) learners were conversant with authority criteria. Further, findings indicated that 27 (44.3\%) B.Ed (Science) trainees were not conversant with authority criteria whereas $34(55.7 \%)$ B.Ed (Science) learners were conversant with the criteria. This suggested that B.Ed (Science) trainees were more conversant with authority criteria than the B.Ed (Arts) learners. The findings in Table 1 affirmed that 16 (51.6\%) trainees pursuing B.Ed (PE \& Sports option) were not conversant with authority criteria whereas 15 (48.4\%) B.Ed (PE \& Sports) learners were conversant with the criteria. Moreover, findings revealed that 12 (85.7\%) B.Ed (Early Childhood Education) trainees were not conversant with authority criteria. The following verbatim findings affirmed that B.Ed (Early Childhood Education) trainees have inadequate evaluating ability: A second year male trainees taking B.Ed (Early Childhood Education) was asked to rate conversance with authority criteria to evaluate credibility of e- resources before utilizing the documents. The reply confirmed trainees' ignorance with regard to authority criteria of evaluating sources for credibility: "I'm not conversant with evaluation of sources". We didn't cover evaluation of information during information skills class. Efforts of requesting my colleagues to explain the evaluation criteria were not fruitful because none was familiar with the topic. Lack of relevant information skills books in the library complicated the matter because the books are outdated and not relevant". This suggested that majority of trainees taking B.Ed (Early Childhood Education) are not conversant with authority criteria and utilize e-resources without evaluating the quality of the information presented by the source. Further findings confirmed that 2 (14.3\%) B.Ed (Early Childhood Education) trainees were conversant with the authority criteria. The findings indicated that B.Ed (PE \& Sports option) trainees are more conversant with authority criteria than B.Ed (Early Childhood Education) colleagues. Further, the findings revealed that $15(37.5 \%)$ B.Ed (ICT) trainees were not conversant with authority criteria whereas 25 (62.5\%) B.Ed (ICT) learners were conversant with the criteria. The findings confirmed that B.Ed (ICT) trainees took lead in being more conversant with evaluation criteria than other cohorts. The B.Ed (ICT) $25(62.5 \%)$ trainees were followed by B.Ed (Science) at $34(55.7 \%)$, B.Ed (PE\& Sports) at 35 (48.4\%), B.Ed (Arts) at $99(46 \%)$ and lastly B.Ed (Early Childhood Education) at $2(14.3 \%)$. The findings indicated that Science teacher trainees, that is, B.Ed (Science) and B.Ed (ICT) were more conversant with evaluating e-resources than Arts trainees that include B.Ed (Arts) and B.Ed (Early Childhood Education). For instance, majority (62.5\%) B.Ed (ICT) trainees were conversant with evaluating e-resources by applying authority criteria whereas only a minority (14.3\%) B.Ed (Early Childhood Education) (Arts) trainees were conversant with the authority criteria. A chi square test 
indicated that there was a statistical significant association between trainees' information evaluating ability and utilization of e-resources $(p<0.05)$. This implied that an improvement in trainees' evaluating ability increases utilization of e-resources by the learners.

\section{Conclusion}

The study established that although the University of Nairobi has availed a wide range of e-resources to support trainees' academic work, majority of B.Ed (Arts), B.Ed (PE and Sports option) and B.Ed (Early Childhood Education) trainees were not conversant with evaluation criteria. This situation hampers utilization of e-resources by the trainees. The study revealed that trainees experienced difficulties when evaluating e-resources for accuracy, currency, coverage, authority and objectivity. Conversance with the evaluation criteria would promote utilization of e-resources because trainees familiar with the topic would consult eresources before extracting quality information. Utilizing quality information extracted from e-resources would enable trainees to develop scholarly articles that improves learners' academic performance. This would be a step in the right direction because the university subscribes a lot of money annually to avail up-to-the-minute information to the trainees to advance knowledge. This implies that the resources spent by the university in subscribing for the e-resources would be utilized in the right way by the trainees. The findings indicated that Science based trainees (B.Ed ICT) and (B.Ed Science) were more conversant with evaluation criteria than art based learners (B.Ed Arts, B.Ed PE and Sports and B.Ed Early Childhood Education. This suggested that science trainees were more familiar with evaluation criteria than art teachers. The study also established that there was a significant statistical association between evaluating ability and utilization of e-resources $(p<0.05)$. This implied that improving the trainees' evaluating ability increases utilization of e-resources by the learners.

\section{Recommendations}

Several recommendations were offered based on the findings of the study. A policy on information literacy training for trainees should be formulated at the University of Nairobi requesting learners to attend all sessions conducted by librarians. The trainees should be guided on evaluation criteria to improve practices of assessing accuracy, currency, coverage, authority and objectivity of information. The evaluation training sessions should take hands-on approach to allow the trainees an opportunity to acquire practical skills of evaluating e-resources. Conversance with evaluation criteria increases utilization of e-resources by trainees to advance academic tasks. Further research should be undertaken at the University of Nairobi to monitor trainees' evaluating ability from first year to fourth year. It is expected that the trainees' evaluating ability improves as the students moves up the ladder of university education from lower to higher levels.

\section{References}

[1] Kanori, J, Odundo, P and Inyega, H. (2018). Influence of bachelor of education teacher trainees' information searching ability on utilization of e-resources at University of Nairobi, Kenya. International Journal of Social Sciences and Humanities Invention, 5, pp. 5179-5186 doi: 10.18535/ijsshi/v5i12.14.

[2] Daugherty, A and Russo, M. (2011). An assessment of the lasting effects of a stand-alone information course: The students' perspective. The Journal of Academic Librarianship, 37, pp. 319-326 doi: 10.1016/j.acalib.2011.04.006.

[3] Rutgers University. (2017). Evaluation criteria for electronic resources. Retrieved on 20th June 2017. From: http://www.libraries.rutgers./edu/rul/staff/collection_dev/r eports/eval_criteria_e- resources.hmtl

[4] Post University. (2017). Evaluating information sources. Retrieved on $7^{\text {th }} \quad$ August 2017. From: http://post.edu/doc/default-source/library/evaluatinginformation

[5] Wasike, J and Simiyu, K. (2015). "Library skills", in B. Nyongesa and I. Simiyu, Eds. Communication skills in institutions of higher learning. Nairobi: Zeed n Cee Publishers

[6] Georgetown University. (2017). Evaluating internet resources. Retrieved on $6^{\text {th }}$ August $2017 . \quad$ From: http://www.library.georgetown.edu/tutorials/researchguide/evaluation

[7] Haridasan, S and Khan, M. (2009). Impact of e-resources by social scientists in National Science Documentation Centre (NASSDOC), India. The Electronic Library, 27, pp. 117-133.

[8] Deng, H. (2010). Emerging patterns and trends in utilizing electronic resources in a higher education environment: An empirical analysis. New Library World, 111, pp. 87-103.

[9] Bhatt, S and Rana, M. (2011). E-information use among engineering academics in India with special reference to Rajasthan State. Library Hi Tech, 29, pp. 496-511.

[10] Chen, H. and Jang, S. (2013). Exploring the reasons for using electric books and technologic pedagogical and content knowledge of Taiwanese elementary mathematics and science teachers. Turkish Online Journal of Educational Technology, 12, pp. 131-141.

[11] Grigson, A. (2011). "An introduction to e-book business models and suppliers", in K. Price and V. Havergal, Eds. Ebooks in libraries: a practical guide. London, UK: Facet Publishing.

[12] Kenchakkanavar, A. (2014). Types of e-resources and its utilities in libraries. International Journal of Information Sources and Services, 1, pp. 97-104.

[13] University of Nairobi. (2019). University of Nairobi research archive. Retrieved on $2^{\text {nd }}$ January 2018. From: https://www.uonbi.ac.ke

[14] Kanori, J. (2019). Influence of information literacy on utilization of electronic resources by bachelor of education teacher trainees, University of Nairobi, Kenya. Unpublished $\mathrm{PhD}$ thesis. University of Nairobi, Nairobi, Kenya. 
[15] Welsh, T and Wright, M (2010). Information literacy in the digital era: An evidence-based approach. Oxford: Chandos Publishing.

[16] University of Alaska Fairbanks. (2017). Evaluating information sources. Retrieved on $5^{\text {th }}$ August 2017. From: https://library.uaf.edu/is101-evaluation

[17] Kanori, J, Odundo, P and Inyega, H. (2018). Relationship between bachelor of education teacher trainees' citation and referencing ability and utilization of e-resources. International Journal of Advanced Research, 6, pp. 1334-1343 doi: $10.21474 /$ IJAR01/8274.

[18] Kodani, L. (2012). Information literacy for electronic resources. Retrieved on $28^{\text {th }}$ October 2015. From: http://laulima.hawaii.edu/.../Laureenkodani_ETEC687_ideaPa perFinal.do

[19] Baro, E., Eze, M. and Nkanu, W. (2013). E-Library services: Challenges and training needs for librarians in Nigeria. OCLC Systems \& Services, 29, pp. 101-116.

[20] Wijetunge, P. (2015). Information resources usage by agriculture undergraduates of the University of Peradeniya, Sri Lanka. Annals of Library and Information Studies, 62, pp. 77-83.

[21] Walraven A., Brand-Gruwel, S and Boshuizen, H. (2009). How students evaluate information and sources when searching the World Wide Web for information. Computers \& Education, 52, pp. 234-46. Retrieved on $11^{\text {th }}$ October 2015. From:

http://dx.doi.org/10.1016/j.compedu.2008.08.00311.10.2015

[22] Curie, L. (2010). Undergraduate search strategies and evaluation criteria: Searching for credible sources. Retrieved on $\quad 4^{\text {th }}$ June $2015 . \quad$ From: http://kuscholarworks.ku.edu/bitsream/.../New_library_world. pdf?..

[23] Head, A and Eisenberg, M. (2009). How today's college students use wikipedia for course-related research, First Monday 15 , pp. 1-2. Retrieved on $16^{\text {th }}$ June 2015. From: http://firstmonday.org/ojs/index.php/fm/article/view/2830/247 6

[24] Oregon State University Libraries. (2017). Undergraduate information literacy competencies. Retrieved on $9^{\text {th }}$ June 2017. From: http://osulibrary.oregonstate.edu/instruction/ug_comp.html

[25] Nierenberg, E. (2017). A comparison of nursing and teacher education students' information literacy learning. Results from Norway. Norway: Hedmark University of Applied Sciences.

[26] Kobzina, N (2010). A faculty-librarian partnership: A unique opportunity for course Integration. Journal of Library Administration, 50, pp. 293-314.

[27] Aldac, R and Stearns, T. (1987). Management. Cincinnati, Ohio: South-Western Publishing Co.

[28] Saleemi, N. (2006). Systems theory and management information systems simplified (rev ed.). Nairobi: Saleemi Publications.

[29] Cole, G and Kelly, P. (2011). Management theory and practice. London: GP Publishers.

[30] Hadimani, M. and Rajgoli, I. (2010). Assessing information literacy competencies among the undergraduate students of College of Agriculture, Raichur: A case study. DESIDOC Journal of Library and Information Technology, 30, pp. 70-78.

[31] Korobili, S, Malliari, A and Christodoulou, G. (2009). Assessing information literacy skills in Technological Education Institute of Thessalonik, Greece. Reference Services Review, 37, pp. 340-354.

[32] Ogutu, J., Odundo, P and Mwanda, P (2017). Adoption of information communication and technology on historical research at the University of Nairobi: Implication on teaching and learning process. Asian Journal of Educational Research, 5, pp. 22-31. 